American J. of Engineering and Applied Sciences 3 (2): 270-276, 2010

ISSN 1941-7020

(C) 2010 Science Publications

\title{
Perceived Kitchen Environment among Malaysian Elderly
}

\author{
Zahari Taha and Ruhaizin Sulaiman \\ Centre for Product Design and Manufacturing, \\ Department of Engineering Design and Manufacturing, \\ Faculty of Engineering, University of Malaya, Lembah Pantai 50603 \\ Kuala Lumpur, Malaysia
}

\begin{abstract}
Problem statement: Kitchen is the most important room in a house. Its environment should be highly conducive especially for the elderly when performing daily kitchen activities. There has been little research focused on the environment quality of the elderly kitchen in Malaysia. Only a few researches have been done on general home environment although our preliminary findings shown that the elderly spend $60 \%$ of their daily time in the kitchen. Due to this concern, a study was conducted to investigate the quality of Malaysian elderly kitchen environment and how they perceive different thermal levels. Approach: The kitchen temperature, humidity and light level were measured as these three variables are important factors in the environmental quality determination. Thirty houses were visited and a set of questionnaire was used to measure elderly task performance. The measured values were then compared to previous recommended findings and comfort level of working environment. Results: The results show that $80 \%$ of the kitchen temperature is higher than $28.43^{\circ} \mathrm{C}$. In terms of brightness level, 56.67\% of the kitchens had lower than 323 lux. But the humidity was found remains within the range. Conclusion: The temperature of Malaysian kitchen is higher than moderate level which contributed to discomfort. The kitchen brightness level is lower than required by the elderly. Both variables could affect to the elderly task performance.
\end{abstract}

Key words: Elderly, kitchen environment, temperature, humidity, light, task performance

\section{INTRODUCTION}

Kitchen is a hub of a house. Many activities are carried out in this space such as sweeping, mopping, meal preparing, cooking, eating, dishes cleaning and so on. As the most important room in a house, its environment should be highly conducive when performing daily kitchen activities. Conducive environment is crucial to anyone in performing daily living activities especially for the elderly person. Furthermore bad environment can harm our health.

Temperature and humidity are two important factors in maintaining optimal comfort levels and good indoor air quality. On the other hand, insufficient of light source in a working area can affect a task performance. Therefore, it is important to investigate the combination of these three factors in order to suggest the right kitchen environment.

Light: The quality of light, both natural and artificial, adds vitality to neutral surroundings (Conran, 2002).
We need different level of light brightness as we getting older. At the age of 60 years old, we need two to three times of the light brightness as we needed at the age of 20 and also more shielding and diffusers since older eyes are more sensitive to glare (Bliss, 2006).

There are many different units for measuring light. Some of the common terms are candela, footcandle, lumen and lux. 'Lux' unit which is also called 'metercandle' is the measurement used for this data recording. One lux is equal to 0.0929 footcandles. The brightness of one candle at a distance of one foot is approximately 10.7639 lux.

Temperature: The ability to thermoregulate typically decreases with age. This is strongly related to decreases in physical fitness and increases in the incidence of disabilities with aging. The reduced thermoregulatory capacity leads to increased mortality and morbidity. Heat stroke, hypothermia, increased number of falls, and in-home drowning are some of the problems that are identified to be associated with this reduced

Corresponding Author: Ruhaizin Sulaiman, Centre for Product Design and Manufacturing,

Department of Engineering Design and Manufacturing, Faculty of Engineering, University of Malaya,

Lembah Pantai 50603 Kuala Lumpur, Malaysia Tel: +603-79675369 Fax:+603-79675330 
thermoregulatory capacity (Havenith, 2001). Temperature is one of the principal parameters of thermodynamics. In physics, temperature is a physical property of a system that underlies the common notions of hot and cold. Temperature unit is measured either by Kelvin scale, Celsius of Fahrenheit. To convert Celsius to Kelvin, the following equation can be used:

$$
\mathrm{K}=\left[{ }^{\circ} \mathrm{C}\right]\left(\frac{1 \mathrm{~K}}{1^{\circ} \mathrm{C}}\right)+273.15 \mathrm{~K}
$$

To convert Fahrenheit to Celsius and vice versa these conversion formulas may be used:

$$
\begin{aligned}
& \mathrm{C}=\frac{5}{9}(\mathrm{~F}-32) \\
& \text { and } \\
& \mathrm{F}=\frac{9}{5} \mathrm{C}+32
\end{aligned}
$$

In this study, the degree of Celsius $\left({ }^{\circ} \mathrm{C}\right)$ is used for data recording.

Humidity: Humidity is the amount of water vapor in the air. In layman's terms, "humidity" is normally taken to mean relative humidity. Relative humidity is defined as the ratio of the partial pressure of water vapor in a parcel of air to the saturated vapor pressure of water vapor at a given temperature. Relative humidity is expressed as a percentage and is calculated in the following manner:

$$
\mathrm{RH}=\frac{\mathrm{p}\left(\mathrm{H}_{2} \mathrm{O}\right)}{\mathrm{p}^{*}\left(\mathrm{H}_{2} \mathrm{O}\right)} \times 100 \%
$$

Where:

$$
\begin{aligned}
\mathrm{p}\left(\mathrm{H}_{2} \mathrm{O}\right)= & \text { partial pressure of water vapor in the gas } \\
& \text { mixture } \\
\mathrm{p}^{*}\left(\mathrm{H}_{2} \mathrm{O}\right)= & \begin{array}{l}
\text { Saturation vapor pressure of water at the } \\
\text { temperature of the gas mixture }
\end{array} \\
\mathrm{RH}= & \begin{array}{l}
\text { Relative humidity of the gas mixture being } \\
\text { considered }
\end{array}
\end{aligned}
$$

Objective: The objective of this study is to investigate the quality of Malaysian elderly kitchen environment and how they perceived with different thermal and brightness levels. This involves the measurement of light, temperature and humidity. Analyzing these data will identify whether elderly perform daily kitchen tasks in good or bad condition. The result will be compared to the previous findings and standards to see the differences as well as the comfort level of working spaces.

\section{MATERIALS AND METHODS}

Method: The study was took place in $\mathrm{Kg}$. Sg. Merab residential area in the district of Kajang. Thirty elderly subjects (15 male, 15 female) participated in the survey. They are aged between 60-83 years with the mean of age at 67.1 years. Each of their homes was visited and three environmental measurements were taken from each kitchen. The measurements are light, temperature and humidity as mentioned in the research objective. The data collection was done on the daytime. Each type of measurements was taken 3 times and the average is recorded for analysis. Data was analyzed using statistic method (SPSS 16.0).

Site location: Located in the district of Kajang in the state of Selangor, Sg. Merab consists of 4 villages. They are Kg. Sg. Merab Luar, Kg. Sg. Merab Hulu, $\mathrm{Kg}$. Sg. Merab Tengah and Kg. Paya. It is located about $8 \mathrm{~km}$ east of Putrajaya and $25 \mathrm{~km}$ south of capital city of Kuala Lumpur (Fig. 1).

Instruments: The data was collected using extech 45170 , which is standard environmental measuring equipment (Fig. 2). This equipment measures light $(\mathrm{Fc} / \mathrm{Lux})$, temperature $\left({ }^{\circ} \mathrm{C} /{ }^{\circ} \mathrm{F}\right)$ and humidity $(\% \mathrm{RH})$.

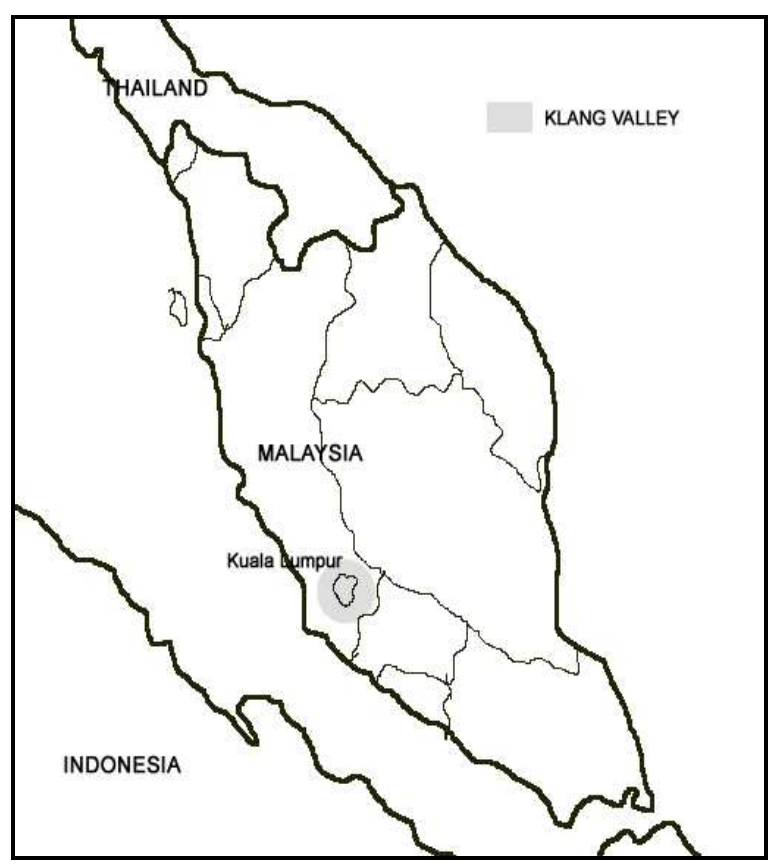

Fig. 1: Site location of the survey 


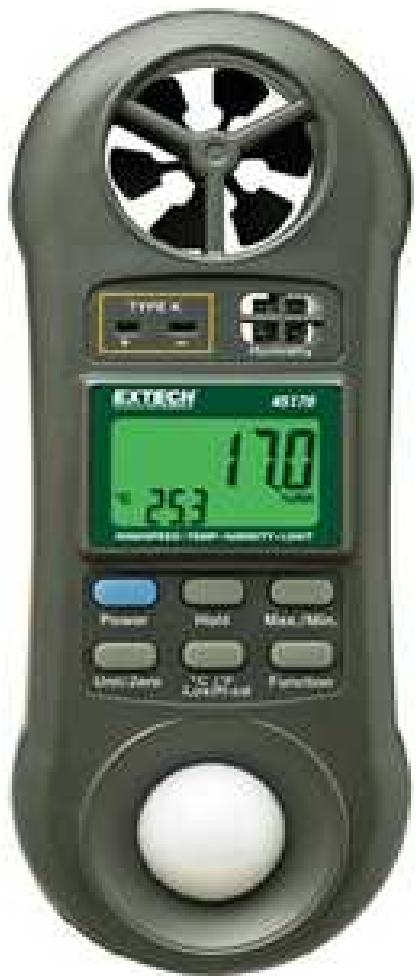

Fig. 2: Instrument used in the data acquisition (EXTECH 45170)

It can also measure air velocity $\left(\mathrm{m} \mathrm{sec}^{-1}\right)$ but this measurement was not included in the study.

\section{RESULTS}

Light: Referring to Fig. 3a, the result of light data distribution is normal. The minimum light reading is 245 lux and the maximum is 524 lux with the mean of 334.43 lux (Fig. $3 \mathrm{~b}$ and Table 1). Table 3 shows the descriptive statistics of the collected light data.

Temperature: The distribution of temperature data is normal as shown in Fig. 4a while Fig. 4b shows the frequency of the data. Table 3 shows the descriptive statistics of the collected temperature data. The result shows that the minimum temperature is $26.9^{\circ} \mathrm{C}$ and the maximum is $35.7^{\circ} \mathrm{C}$ with the mean at $31.15^{\circ} \mathrm{C}$.

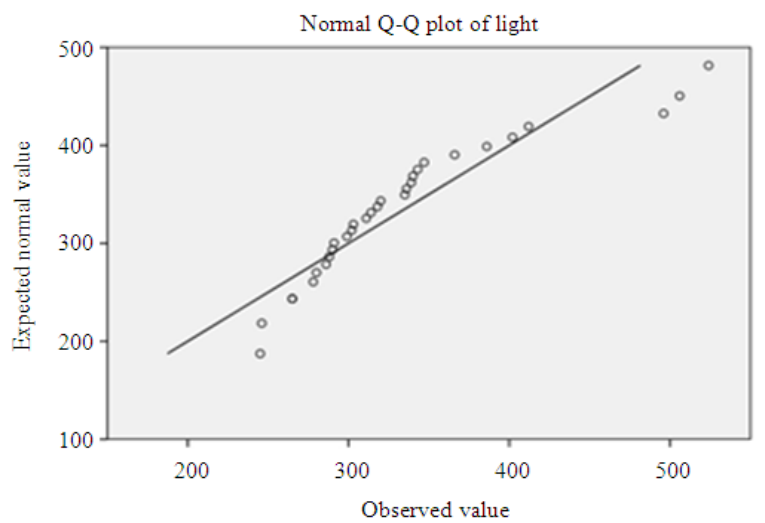

Fig. 3a: Normal distribution of light data

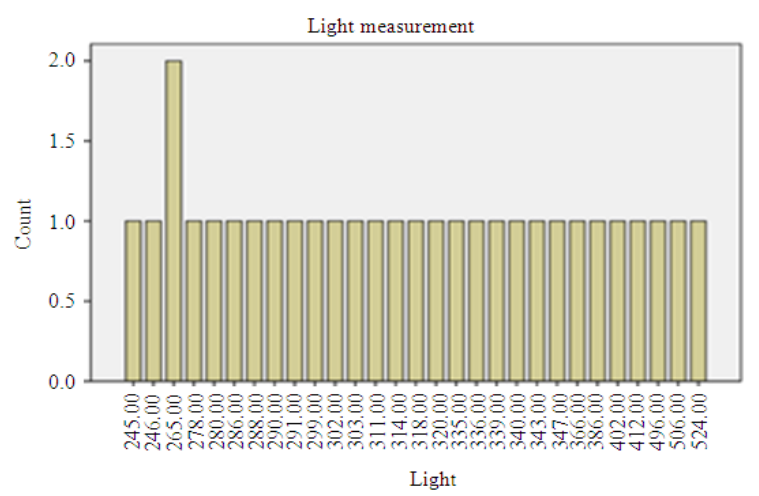

Fig. 3b: Result of kitchen light measurement (Lux)

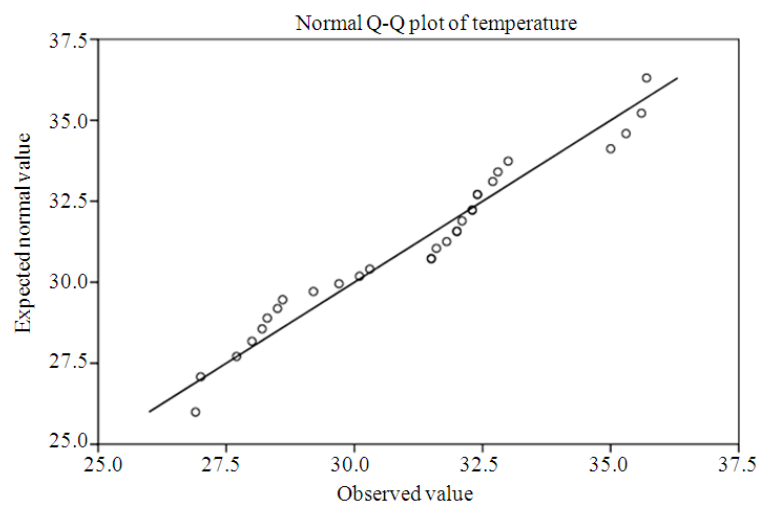

Fig. 4a: Normal distribution of temperature data

Table 1: Recommended lighting levels for kitchen

\begin{tabular}{lll}
\hline Ambient & \multicolumn{1}{c}{ Task } & \multicolumn{1}{c}{ Accent } \\
\hline $\begin{array}{l}\text { Downlights or surface-mounted } \\
\text { ceiling fixtures }(20-30 \mathrm{fc})\end{array}$ & $\begin{array}{l}\text { Undercabinet lighting at counters; downlight } \\
\text { over sink; pendant over } \\
\text { Table. Downlight or minipendants } \\
\text { Over Island or bar. }(30-50 \mathrm{fc}) *\end{array}$ & $\begin{array}{l}\text { Track, eyeball, or wall washers art, note board, } \\
\text { or cookware }(20-30 \mathrm{fc})\end{array}$ \\
& \\
\hline *100 fc for older person working on small detail. Source: (Bliss, 2006) &
\end{tabular}


Table 2: Kitchen light levels

\begin{tabular}{|c|c|c|c|c|c|}
\hline Room/task & & & & & Illumination \\
\hline General & & & & & $300 \operatorname{lux}$ \\
\hline Counter top & & & & & 750 lux \\
\hline Food preparing & & & & & 750 lux \\
\hline Cooking & & & & & $300 \operatorname{lux}$ \\
\hline Dining & & & & & $200 \operatorname{lux}$ \\
\hline Source: About.con & rgon & mics (2 & & & \\
\hline Table 3: Descripti & tisti & of th & in & & \\
\hline $\begin{array}{l}\text { Descriptive } \\
\text { statistics }\end{array}$ & $\mathrm{N}$ & Min & $\operatorname{Max}$ & Mean & SD \\
\hline Light & 30 & 245.0 & 524.0 & 334.4333 & 72.08935 \\
\hline Temperature & 30 & 26.9 & 35.7 & 31.1500 & 2.52761 \\
\hline Humidity & 30 & 53.7 & 84.1 & 70.0033 & 8.84146 \\
\hline Valid N (list wise) & 30 & & & & \\
\hline
\end{tabular}

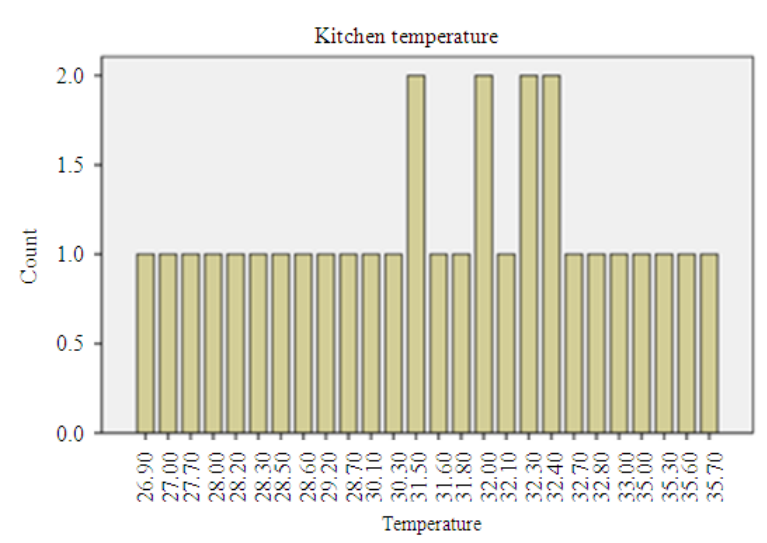

Fig. 4b: Result of kitchen temperature $\left({ }^{\circ} \mathrm{C}\right)$

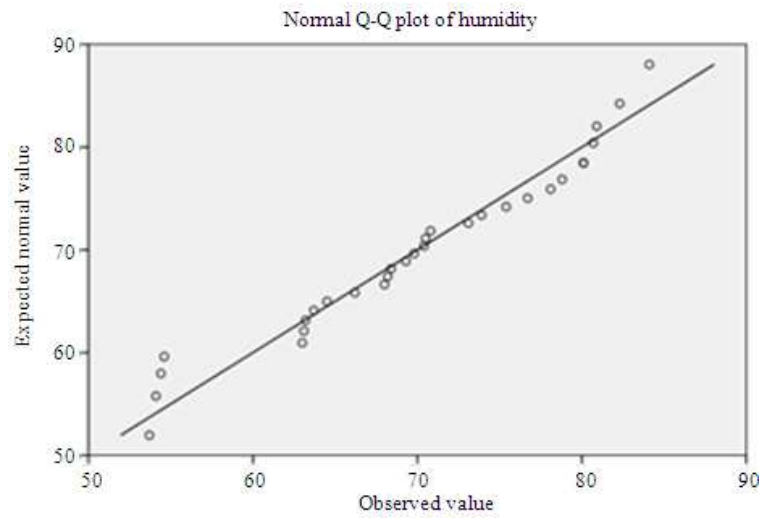

Fig. 5a: Normal distribution of humidity data

Relative humidity: The distribution of humidity data is normal (Fig. 5a). Figure 5b shows the data frequency and Table 3 shows the descriptive statistics of humidity. The relative humidity for all surveyed kitchen is between $53.70-84.10 \% \mathrm{RH}$ with the mean of $70.00 \%$ RH. Therefore, the humidity of elderly surveyed kitchens is found remain at the comfortable level (80\% RH) compared to the above statistics.

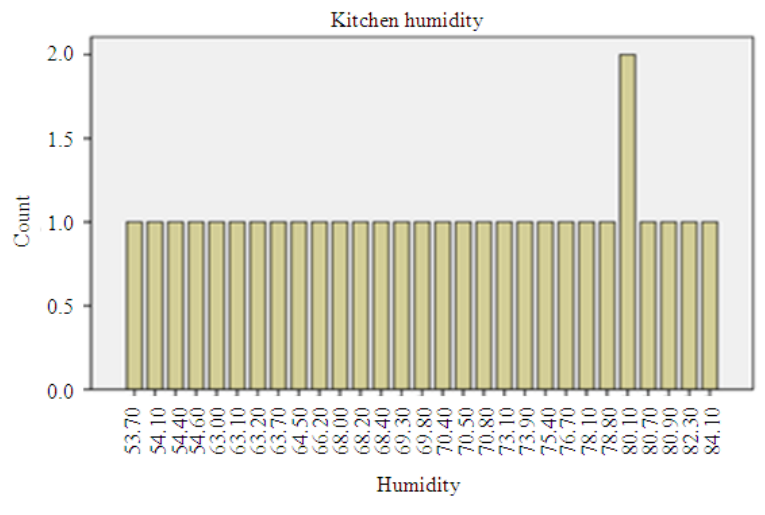

Fig. 5b: Result of kitchen humidity (\%RH)

\section{DISCUSSION}

Light: The fact is elderly need brighter illumination compared to younger age group. Therefore setting up the right artificial light remain important.

The recommended kitchen light level by Bliss (2006) as on Table 1 shows that task performance should be provided by 30-50 fc which is approximately between 323-538 lux. According to About.com: Ergonomics (2009), the cooking and food preparing tasks need 300-750 lux of light level (Table 2).

In comparing the finding with both from Bliss (2006) and About.com: Ergonomics (2009), 36.67\% of the surveyed kitchens are found having inadequate light sources. Poor vision could reduce task performance and this is one of the major contributions to accident or injury in the kitchen.

Therefore, they should be advice to add some fluorescent bulbs to lighten the space as well as overcome these problems.

Temperature: The mean temperature at $31.15^{\circ} \mathrm{C}$ is considered high. Although it would not caused hyperthermia or heat stroke, but the elderly agreed of being less comfort.

Abdul Shukor and Young (1993) found that the preferred climate chamber for Malays is $28.0^{\circ} \mathrm{C}$ while for the Chinese is $28.7^{\circ} \mathrm{C}$. According to Sabarinah et al. (2007) the comfort band of home temperature in Kuala Lumpur is between $23.6-28.6^{\circ} \mathrm{C}$.

Based on the above findings, the average kitchen temperature is $28.43^{\circ} \mathrm{C}$. Referring to this temperature level, it is found that $63.0 \%$ of the surveyed kitchen is exceeded the moderate temperature. This could also reduce the task performance. 
Am. J. Engg. \& Applied Sci., 3 (2): 270-276, 2010

Table 4a: Statistics from 30 subjects

\begin{tabular}{llr}
\hline Controlled temperature & & \\
\hline $\mathrm{N}$ & Valid & 30.00 \\
& Missing & 0.00 \\
& Mean & 2.87 \\
& Std. deviation & 0.63 \\
& Minimum & 2.00 \\
& Maximum & 4.00 \\
\hline
\end{tabular}

Table 4b: Results of 3 different thermo levels. The $22^{\circ} \mathrm{C}$ was not appear since none of the elderly feel comfort and agree with it

\begin{tabular}{lcccc}
\hline $\begin{array}{l}\text { Controlled } \\
\text { temperature }\end{array}$ & Frequency & Percent & Valid $(\%)$ & Cumulative (\%) \\
\hline${\text { Valid } 24^{\circ}}^{\circ}$ & 8 & 26.7 & 26.7 & 26.7 \\
$26^{\circ}$ & 18 & 60.0 & 60.0 & 86.7 \\
$28^{\circ}$ & 4 & 13.3 & 13.3 & 100.0 \\
Total & 130 & 100.0 & 100.0 & \\
\hline
\end{tabular}

Table 5a: Statistics from 30 subjects

\begin{tabular}{llr}
\hline Additional lights & & \\
\hline $\mathrm{N}$ & Valid & 30.00 \\
& Missing & 0.00 \\
& Mean & 2.77 \\
& Std. deviation & 0.82 \\
& Minimum & 1.00 \\
& Maximum & 4.00 \\
\hline
\end{tabular}

Relative humidity: Thermal comfort needs may vary based on climate. In some countries, the recommended level of indoor humidity is in the range of $30-60 \% \mathrm{RH}$ while Malaysia has a common of $80 \%$ RH. Although the mean is lower than usual $(70.00 \% \mathrm{RH})$ but this remain acceptable for Malaysian (Table 3and Fig. 5b).

According to relative humidity report from 38 Meteorological Stations in Malaysia (Wednesday, 18 November 2009), there are low and high humidity classifications. The mean of 'high' is $93.26 \%$ and the 'low' is $88.50 \% \mathrm{RH}$ make average means of $90.88 \%$ $\mathrm{RH}$. This is due to monsoon changes.

Validation: Validation of the result is done through thermo setup and analysis of questionnaire survey by revisiting all thirty houses. A portable air conditioner is used to set the kitchen thermo within $22.0-28.0^{\circ} \mathrm{C}$. A set of 4 portable fluorescent lights are used to brighten the kitchen up to 900 lux. Both means $\left(26.1^{\circ} \mathrm{C}\right.$ and 750 lux) are used as referral point to start off the questionnaire of their preferences. Again the Likert scale (1-5 level) was used for data acquisitions and statistical analysis.

Validation result for thermal comfort: Result as in Fig. 6, Table $4 \mathrm{a}$ and $4 \mathrm{~b}$ show that the elderly preferred to have cooler temperature than at their present state, but they rejected temperature below than $24^{\circ} \mathrm{C}$. The $26^{\circ} \mathrm{C}$ became the elderly thermal level preferences.
Table 5b: Percentage based on 4 different light levels

\begin{tabular}{lrccc}
\hline $\begin{array}{l}\text { Additional } \\
\text { lights }\end{array}$ & Frequency & Percent & Valid (\%) & Cumulative (\%) \\
\hline Valid 600 lux & 2 & 6.7 & 6.7 & 6.7 \\
700 lux & 8 & 26.7 & 26.7 & 33.3 \\
800 lux & 15 & 50.0 & 50.0 & 83.3 \\
900 lux & 5 & 16.7 & 16.7 & 100.0 \\
Total & 30 & 100.0 & 100.0 & \\
\hline
\end{tabular}

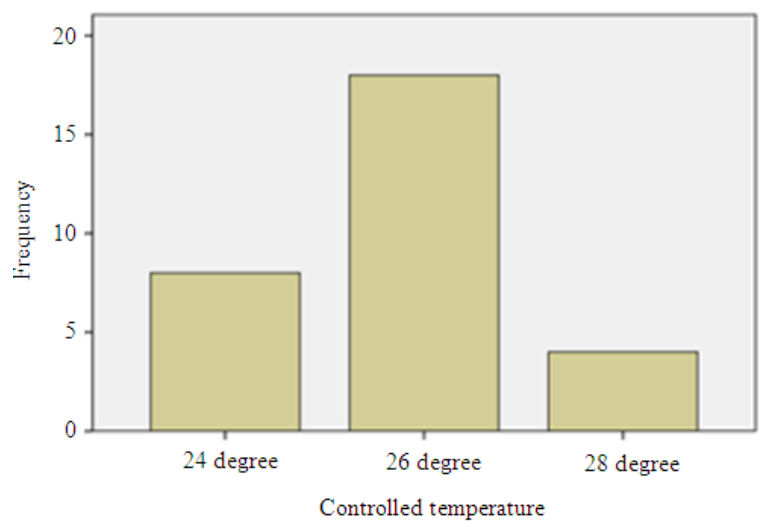

Fig. 6: Frequency based on 3 different thermo levels

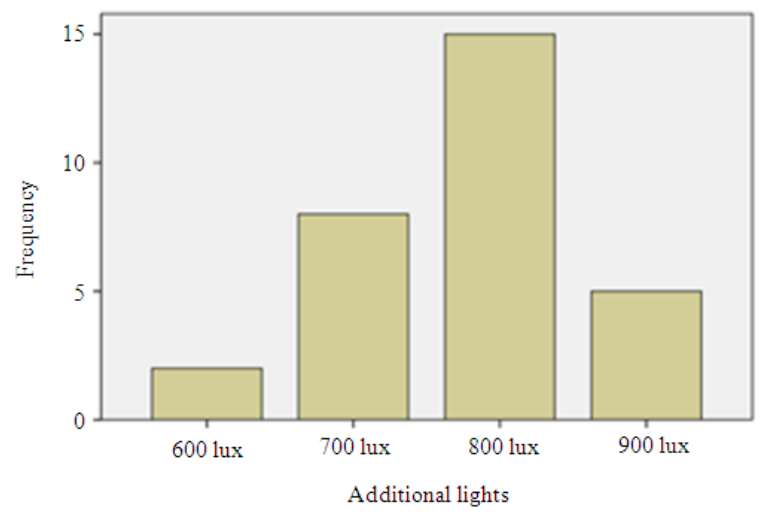

Fig. 7: Frequency based on 4 different light levels

Validation result for light: Figure 7, Table $5 \mathrm{a}$ and $5 \mathrm{~b}$ below show the results after testing four different light levels.

Most of the elderly preferred to have brighter ambient compared to their present light levels. The 800lux received the highest frequency followed by 700 and 900 lux brightness level. These reflect how the elderly perceived with brightness during task performing.

Recommendations: The kitchen space should be within an acceptable thermal condition. As in International Standard (ISO 7730) human occupation is 
divided into 3 levels; hot, moderate and cold environment. The acceptable thermal level suggested by American Society of Heating and Refrigerating Engineers (ASHRAE 55) is also categorized into 3 levels; slightly warm, neutral and slightly cool. In this contact a kitchen is required to have a moderate or neutral thermal environment. The room temperature for Malaysian elderly kitchen, is suggested at $26^{\circ} \mathrm{C}$. This is a bit lower than the previous study $\left(26.1-28.35^{\circ} \mathrm{C}\right)$ since the cooking activities generate additional heat to the room. The relative humidity for $26.1{ }^{\circ} \mathrm{C}$ is about $84 \% \mathrm{RH}$ and at $28.35^{\circ} \mathrm{C}$ it is $78 \% \mathrm{RH}$.

It is suggested that to reduce kitchen temperature, additional windows or ventilation system should be provided. On the other hand, some kitchen should be mounted with ceiling panels to prevent heat from the roof as well as fixing the ceiling fan. These could also help to normalize the humidity of the kitchen by improving the air flow. For the day cooking, normal light from the additional windows will improve visibility as well as saving the electricity consumption. Additional fluorescent lights could increase visibility during the night cooking especially during the month of Ramadan (fasting month) where Muslim elderly wake up for preparing the pre-dawn meal.

Basically, kitchen requires 'task type' of lighting. It should provide bright, but not harsh lighting and the entire food preparation area should be evenly lit with no shadows or dead spots. Ambient lighting fills the room with general lighting which provides the key lighting for the room. Ambient lighting helps to eliminate or softens shadows and makes people feel welcome in a kitchen. As the elderly need two or three times brighter light level, their kitchen light level should be within 600-900 lux. This will fit both specific tasks and general activities in the kitchen.

Limitation of research: The fabricated light control is using 6 fluorescent (4ft long bulbs) fixed with reflector and casing. Each bulb had an individual switch. To get 600 lux, 3 bulbs are switched on. For 700 lux 4 bulbs are used. For 800 lux we use 5 bulbs and to reach brightest 900 lux all 6 bulbs are used. This is applied to a room at the size of 10 by $20 \mathrm{ft}$. with bright wall and ceiling paint. The main problem occurred when we try to get the exact brightness setting that we wanted. The brightness setting is difficult to achieve and it may caused by several factors. First, the voltage drop for each bulb. Second, the size of spaces that need to be lit which varies from one kitchen to another. Third, the dark colored plank wall that absorb light and reduce luminance. To overcome this problem, estimation was applied to all 4 brightness level with \pm 20 lux.
Meanwhile, the kitchen cooling-down process also take a longer time especially to the larger kitchens. Furthermore each temperature setting requires the subject to get in and out from the room. These limit the number of visited houses to maximum of only $3 \mathrm{day}^{-1}$.

\section{CONCLUSION}

Based on the findings, it can be concluded that there was a positive correlation between the three variables towards comfortability and task performance. Providing sufficient light source, right room temperature and humidity could help the elderly to perform better in their kitchens. Secondly, the temperature and light controlled method is found useful in validating elderly percipient on both variables. The relative humidity was not validated since it is closely related to temperature setting. Finally, the questionnaire can be used to measure the elderly task performance.

The findings could be generalized for Malaysian elderly population since they had many similarities especially in terms of breakdown of functional impairments. These including changes in anthropometry, musculoskeletal attributes, respiration and circulation, nervous functions, capacity for physical work, brain and memory, visual functions, hearing, taste and smell, sensitivity and also sensory and psychomotor performance. Either they live independently at their home setting or dependently at old folk homes; these physical, biomechanical and physiological issues are remain the same. Furthermore they live at the same climatic.

Application of the findings is hopefully could increase Malaysian elderly task performing, minimize the kitchen accident rate through visual improvement and generally promote "living-in-place" among Malaysian elderly.

\section{ACKNOWLEDGEMENT}

The researcher thanked to all voluntarily participated elderly in this study. This research was funded under University Malaya research grant No. IPPP/UPPiT/Geran (RU/PPP) PS040/2008A.

\section{REFERENCES}

Abdul Shukor, A.M. and A. Young, 1993. Thermal comfort study as an aid to determine energy savings in buildings in Malaysia. Proceeding of the 5th International Energy Conference, (IEC'93), Seoul, Korea, pp: 261-267. 
About.com: Ergonomics, 2009. Lighting. Sabarinah, S.A., I.Z. Nor Zaini, S.M. Mohammad and http://ergonomics.about.com/od/lighting

Bliss, S., 2006. Best Practices Guide to Residential Construction: Materials, Finishes and Details. John Wiley and Sons Inc., New Jersey, ISBN: 13: 9780-471-64836-9, pp: 197.

Conran, T., 2002. Kitchen: The Hub of the Home. Octopus Publishing Group, London, ISBN: 184091-233-2, pp: 70.

Havenith, G., 2001. Temperature regulation and technology. Gerontechnology, 1: 41-49. DOI: 10.4017/gt.2001.01.01.004.00 G.S. Mohd, 2007. Achieving thermal comfort in Malaysian building: bioclimatic housing. Proceeding of the Building Industry's Solution to Sustainable Development, Aug. 7-7, Putra World Trade Centre, Kuala Lumpur, Malaysia, pp: 51-63. http://malaysianpublications.blogspot.com/2009/12 /sabarinah-shahmad-uitm-phd-achieving.html 